\title{
Exogenous spermine inhibits the proliferation of human pulmonary artery smooth muscle cells caused by chemically-induced hypoxia via the suppression of the ERK1/2- and PI3K/AKT-associated pathways
}

\author{
CAN WEI ${ }^{1}$, HONG-ZHU LI ${ }^{1}$, YUE-HONG WANG ${ }^{1}$, XUE PENG $^{1}$, HONG-JIANG SHAO $^{1}$, HONG-XIA LI ${ }^{1}$, \\ SHU-ZHI BAI ${ }^{1}$, XIAO-XIAO LU ${ }^{2}$, LING-YUN WU ${ }^{1,3}$, RUI WANG $^{1,4}$ and CHANG-QING XU ${ }^{1}$ \\ ${ }^{1}$ Department of Pathophysiology, Harbin Medical University, Harbin, Heilongjiang 150081; \\ ${ }^{2}$ Department of Ultrasound, The First Affiliated Hospital of Jiamusi University, Jiamusi, Heilongjiang 154007, P.R. China; \\ Departments of ${ }^{3}$ Biology and ${ }^{4}$ Health Sciences, Lakehead University, Thunder Bay, Ontario P7B 5E1, Canada
}

Received May 13, 2015; Accepted November 6, 2015

DOI: $10.3892 / \mathrm{ijmm} .2015 .2408$

\begin{abstract}
Pulmonary vascular remodeling is a significant pathological feature of hypoxia-induced pulmonary hypertension (HPH), while pulmonary artery smooth muscle cell (PASMC) proliferation plays a leading role in pulmonary vascular remodeling. Spermine (Sp), a polyamine, plays a critical role in periodic cell proliferation and apoptosis. The present study was conducted to observe the association between hypoxia-induced PASMC proliferation and polyamine metabolism, and to explore the effects of exogenous $\mathrm{Sp}$ on PASMC poliferation and the related mechanisms. In the present study, PASMCs were cultured with cobalt chloride $\left(\mathrm{CoCl}_{2}\right)$ to establish a hypoxia model, and $\mathrm{Sp}$ at various final concentrations $(0.1,1,10$ and $100 \mu \mathrm{M})$ was added
\end{abstract}

Correspondence to: Professor Chang-Qing Xu, Department of Pathophysiology, Harbin Medical University, 157 Baojian Road, Harbin, Heilongjiang 150081, P.R. China

E-mail: xucq45@126.com

Abbreviations: Sp, spermine; HPH, hypoxia-induced pulmonary hypertension; PASMCs, pulmonary artery smooth muscle cells; $\mathrm{CoCl}_{2}$, cobalt chloride; DMEM, Dulbecco's modified eagle's medium; FBS, fetal bovine serum; ODC, ornithine decarboxylase; SSAT, spermidine/spermine N1-acetyltransferase; CCK-8, cell counting kit-8; MTT, 3-(4,5-dimethylthiazol-2-yl)-2,5-diphenyltetrazolium bromide; BrdU, 5-bromo-2'-deoxy-uridine; AKT, protein kinase B; PI3K, phosphatidylinositol 3-kinase; ERK1/2, extracellular signal-regulated kinase $1 / 2$; PDGF, platelet-derived growth factor; MAPK, mitogen-activated protein kinase; CDKIs, cyclin-dependent kinase inhibitors; CDK, cyclin-dependent kinases

Key words: spermine, pulmonary artery smooth muscle cells, proliferation, chemical hypoxia, extracellular signal-regulated kinase 1/2, phosphatidylinositol 3-kinase/protein kinase B to the medium of PASMCs $40 \mathrm{~min}$ prior to the induction of hypoxia. Cell proliferation was measured by 3-(4,5-dimethylthiazol-2-yl)-2,5-diphenyltetrazolium bromide (MTT) assay, cell counting kit-8 assay and 5-bromo-2'-deoxyuridine (BrdU) incorporation assay. Cell cycle progression was determined by flow cytometry, and the protein expression levels of spermidine/spermine N1-acetyltransferase (SSAT; the key enzyme in the terminal degradation of polyamine), ornithine decarboxylase (ODC; the key enzyme of polyamine biosynthesis), cyclin D1 and p27 were measured by western blot analysis. The results revealed that the proliferation of the PASMCs cultured with $\mathrm{CoCl}_{2}$ at $50 \mu \mathrm{M}$ for $24 \mathrm{~h}$ markedly increased. The expression of ODC was decreased and the expression of SSAT was increased in the cells under hypoxic conditions. Exogenous $\mathrm{Sp}$ at concentrations of 1 and $10 \mu \mathrm{M}$ significantly inhibited hypoxiainduced PASMC proliferation, leading to cell cycle arrest at the G1/G0 phase. In addition, Sp decreased cyclin D1 expression, increased p27 expression, and suppressed the phosphorylation of extracellular signal-regulated kinase 1/2 (ERK1/2), phosphatidylinositol 3-kinase (PI3K) and protein kinase B (AKT); however, the above-metioned parameters were not markedly affected by Sp at concentrations of 0.1 or $100 \mu \mathrm{M}$. These results suggest that hypoxia disrupts polyamine metabolism, and $\mathrm{Sp}$ at concentrations of 1 and $10 \mu \mathrm{M}$ inhibits the increase in human PASMC proliferation caused by chemically-induced hypoxia via the suppression of the ERK1/2- and PI3K/AKT-associated pathways. This study thus offer new insight into the prevention and treatment of HPH.

\section{Introduction}

Chronic hypoxia-induced pulmonary hypertension (HPH), an incurable disease, is often a complication in patients with chronic heart failure, chronic obstructive pulmonary disease and sleep apnea (1). Pulmonary arterial remodeling, a marker of severe and advanced $\mathrm{HPH}$, is primarily attributed to the abnormal proliferation of pulmonary artery smooth muscle cells (PASMCs) $(2,3)$. Thus, the inhibition of the aberrant 
proliferation of PASMCs may prove to be a novel therapeutic strategy for the treatment of HPH.

Cyclin D1 and its associated cyclin-dependent kinases (CDKs) are regulated proteins which are key in controlling the re-entry of quiescent cells from the G0 to the G1 phase (4). p27 blocks the G1-S transition in the cell cycle, and is a negative regulator of the protein kinases, cyclin/CDK (5). The interaction of the two factors regulates cell proliferation and apoptosis (6). The activity of extracellular signal-regulated kinase 1/2 (ERK1/2), a major mitogenic signaling pathway, has been shown to be significantly enhanced in a variety of animal models of pulmonary arterial hypertension (7). Previous studies have revealed that 5-hydroxytryptamine (5-HT) and platelet-derived growth factor (PDGF) induce the proliferation of PASMCs through the activation of the phosphatidylinositol 3-kinase (PI3K)-protein kinase B (AKT) signaling pathways $(8,9)$. Therefore, blocking these signaling pathways may play a key role in the prevention and treatment of HPH.

Spermine (Sp), a polyamine, is a non-protein small molecule with polyvalent positive charges and nitrogen. Polyamine homeostasis is of great importance for cell survival (10). Ornithine decarboxylase (ODC) is the key enzyme of polyamine biosynthesis, and spermidine/spermine N1-acetyltransferase (SSAT) is the key enzyme in the terminal degradation of polyamides. They are both associated with the regulation of polyamine metabolism (11). However, to the best of our knowledge, the role which Sp plays in PASMC proliferation has not yet been elucidated. Cobalt chloride $\left(\mathrm{CoCl}_{2}\right)$ is a well-known hypoxia-mimetic agent that mimics the hypoxic response in many aspects (12). Therefore, in the present study, we established a hypoxia model by culturing PASMCs with $\mathrm{CoCl}_{2}$, and then observed the changes in polyamine metabolism following hypoxia. In addition, we examined the effects of exogenous Sp on PASMC proliferation and the underlying mechanisms.

\section{Materials and methods}

Materials. Sp was purchased from Sigma-Aldrich (St. Louis, MO, USA). 5-Bromo-2'-deoxyuridine (BrdU) Labeling reagent and the Detection Kit I were obtained from Roche Diagnostics GmbH (Mannheim, Germany). Anti-cyclin D1 and anti-p27 antibodies were from Santa Cruz Biotechnology, Inc. (Santa Cruz, CA, USA). Anti-mitogen-activated protein kinase (MAPK), anti-PI3K p85 and anti-AKT antibodies were all purchased from Cell Signaling Technology, Inc. (Danvers, MA, USA). Alkaline phosphatase-labeled goat anti-rabbit IgG antibody and goat anti-mouse IgG antibody were both from Sigma-Aldrich.

Cell culture. Normal human PASMCs were acquired from the American Type Culture Collection (PCS-100-023; ATCC, Mannassas, VA, USA. We subcultured the cells, and cells at the 4th to 9 th passages were used in our experiments. The medium was composed of high glucose Dulbecco's modified Eagle's medium (DMEM), 10\% fetal bovine serum (FBS) and $1 \%$ penicillin or streptomycin at $37^{\circ} \mathrm{C}$, in a humidified incubator with $5 \% \mathrm{CO}_{2}$. After being conventionally cultured for $48 \mathrm{~h}$, the cells were serum-starved for $24 \mathrm{~h}$ in serum-free medium. The control group consisted of cells cultured with no special treatment for the next $24 \mathrm{~h}$, whereas the hypoxia group was cultured in with serum-free medium with $50 \mu \mathrm{M} \mathrm{CoCl}_{2}$, and the treatment groups were treated with various concentrations $(0.1,1,10$ and $100 \mu \mathrm{M})$ of $\mathrm{Sp}$ for $40 \mathrm{~min}$ prior to the induction of hypoxia.

Cell viability assay. Cell viability was measured using a Cell Counting Kit-8 (CCK-8; Dojindo, Kumamoto, Japan). The PASMCs were seeded in 96-well plates at a density of $3 \times 10^{3}$ cells/ well. After being serum-starved for $24 \mathrm{~h}$, various concentrations of $\mathrm{CoCl}_{2}(10,25,50,100,300,600$ and $1,000 \mu \mathrm{M})$ were added to the medium and the cells were cultured for 6,12 and $24 \mathrm{~h}$, respectively. We then used a microplate spectrophotometer (BMG LABTECH, Offenburg, Germany) to detect the optical density (OD) at $450 \mathrm{~nm}(\mathrm{~A} 450)$.

Cell proliferation assay. PASMC proliferation was measured by 3-(4,5-dimethylthiazol-2-yl)-2,5-diphenyltetrazolium bromide (MTT) assay, CCK-8 assay and BrdU incorporation assay. For MTT assay, the cells were seeded in 96-well plates at a density of $1 \times 10^{3}$ cells/well. The proliferation of the PASMCs in the control, hypoxia and treatment groups was measured. The operating protocols were according to the instructions provided by the manufacturer of the MTT kit (Boster Institute of Biotechnology, Wuhan, China). The absorbance [optical density (OD)] at $490 \mathrm{~nm}$ (A490) was measured using a microplate spectrophotometer.

For CCK-8 assay, the cells were seeded in 96-well plates at a density of $3 \times 10^{3}$ cells/well. At the end of the treatment period, $10 \mu \mathrm{l} \mathrm{CCK}-8$ was added to each well followed by incubation for $1.5 \mathrm{~h}$ at $37^{\circ} \mathrm{C}$. Subsequently, we detected the OD value at $450 \mathrm{~nm}$ (A450) using a microplate spectrophotometer.

For BrdU incorporation assay, the cells were seeded in 12-well plates at a density of $3 \times 10^{4}$ cells/well. BrdU was incorporated in proliferating cells according to the manufacturer's instructions (Roche Diagnostics $\mathrm{GmbH}$ ). For evaluation by fluorescence microscopy (Nikon Corp., Tokyo, Japan), we used an excitation wavelength in the range of 450-500 $\mathrm{nm}$ and detection in the range of $515-565 \mathrm{~nm}$.

Cell cycle analysis. In the present study, cell cycle progression was determined by flow cytometry. The cells were harvested with $0.25 \mathrm{~g} / 1$ trypsin in 6-well plates, re-suspended in $10 \mathrm{ml} \mathrm{PBS,} 1 \mathrm{ml} \mathrm{70 \%} \mathrm{ethanol} \mathrm{was} \mathrm{added,} \mathrm{and} \mathrm{the} \mathrm{cells}$ were then centrifuged $\left(2,000 \mathrm{rpm}, 5 \mathrm{~min}, 4^{\circ} \mathrm{C}\right)$ and washed with cold PBS. The cells were subsequently dyed with $100 \mu \mathrm{l}$ RNAse $(1 \mathrm{mg} / \mathrm{ml})$ and then $400 \mu \mathrm{l} \mathrm{PI}(20 \mu \mathrm{g} / \mathrm{ml})$. Following incubation for $30 \mathrm{~min}$ at room temperature, the samples were run on a 7 Laser SORP BD LSR II system (BD Biosciences, Franklin Lakes, NJ, USA) and the data was analyzed using CellQuest software (BD Biosciences).

Western blot analysis. The cells were harvested and then lysed. Equal amounts of proteins were boiled and separated with sodium dodecyl sulfate-polyacrylamide gel electrophoresis (SDS-PAGE) and electrophoretically transferred to nitrocellulose membranes. Equal amounts of proteins were loaded into each lane of a 10\% SDS-PAGE gel, electrophoresed and transferred onto membranes. The membranes were blocked with Tris-buffered saline (TBS) containing 5\% non-fat 


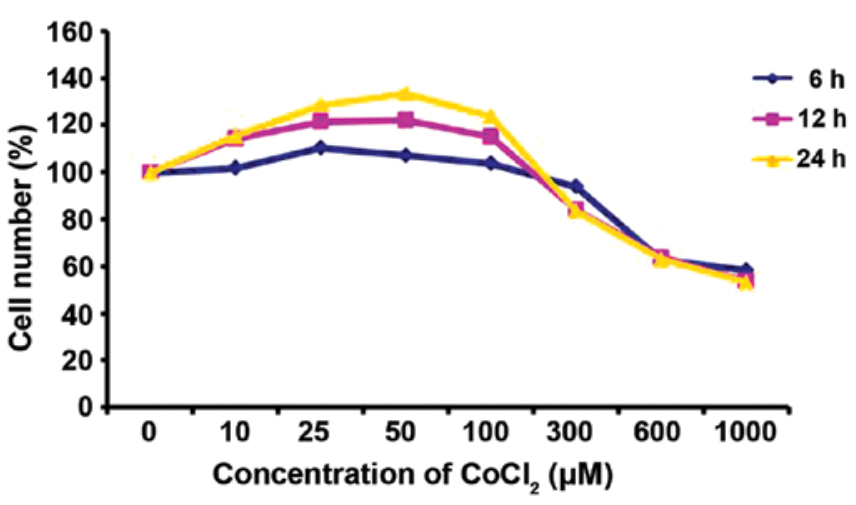

Figure 1. Effect of various concentrations of $\mathrm{CoCl}_{2}$ and treatment times on the number of pulmonary artery smooth muscle cells (PASMCs). The number of PASMCs was detected by CCK-8 assay. The number of cells increased at a concentration of 10-100 $\mu \mathrm{M}$, and decreased at a concentration of 300-1,000 $\mu \mathrm{M}$ in a time-dependent manner. The cells incubated with control medium were considered $100 \%$ viable. Data are presented as the means \pm SEM of 8 determinations.

milk at room temperature for $1 \mathrm{~h}$, and then incubated overnight at $4^{\circ} \mathrm{C}$ with the primary antibodies. The primary antibody dilutions were as follows: 1:1,000 for ODC, SSAT, cyclin D1, p27, phosphorylated (p-) or total ERK, PI3K, AKT and 1:10,000 for $\beta$-actin. The membranes were incubated in TBST solution with alkaline phosphatase-labeled secondary antibody (diluted 1:5,000) for $1 \mathrm{~h}$ at room temperature on a shaker. Finally, antibody-antigen complexes were detected using Western Blue Stabilized Substrate (Promega, Madison, WI, USA) for alkaline phosphatase. The intensities of the protein bands were quantified using a Bio-Rad ChemiDoc ${ }^{\mathrm{TM}}$ EQ densitometer and Bio-Rad Quantity One software (Bio-Rad Laboratories, Hercules, CA, USA).

Statistical analysis. All data are expressed as the means $\pm \mathrm{SE}$ and represent at least 3 independent experiments. Statistical comparisons were made using a paired or unpaired t-test, and one-way analysis of variance (ANOVA). A p-value $<0.05$ was considered to indicate a statistically significant difference.

\section{Results}

Effect of $\mathrm{CoCl}_{2}$ on PASMC viability. The results of the CCK-8 assay indicated that the number of PASMCs firstly increased and then decreased in a concentration and time-dependent manner. The cells incubated in control medium were considered $100 \%$ viable. $\mathrm{CoCl}_{2}$ at a concentration of $10-100 \mu \mathrm{M}$ increased the proliferation of the PASMCs, and this trend was particularly evident when the cells were incubated with $50 \mu \mathrm{M} \mathrm{CoCl}_{2}$ for $24 \mathrm{~h}$; however, when the cells were incubated with $\mathrm{CoCl}_{2}$ at a concentration of $300-1,000 \mu \mathrm{M}$, the number of viable PASMCs notably decreased (Fig. 1).

Changes to the key regulatory enzyme of polyamine metabolism under hypoxic conditions. ODC is an enzyme that performs the first step in polyamine biosynthesis; SSAT is the key regulatory enzyme for polyamine catabolism $(13,14)$. Compared with the control group, the expression of ODC was decreased and that of SSAT was significantly increased in the
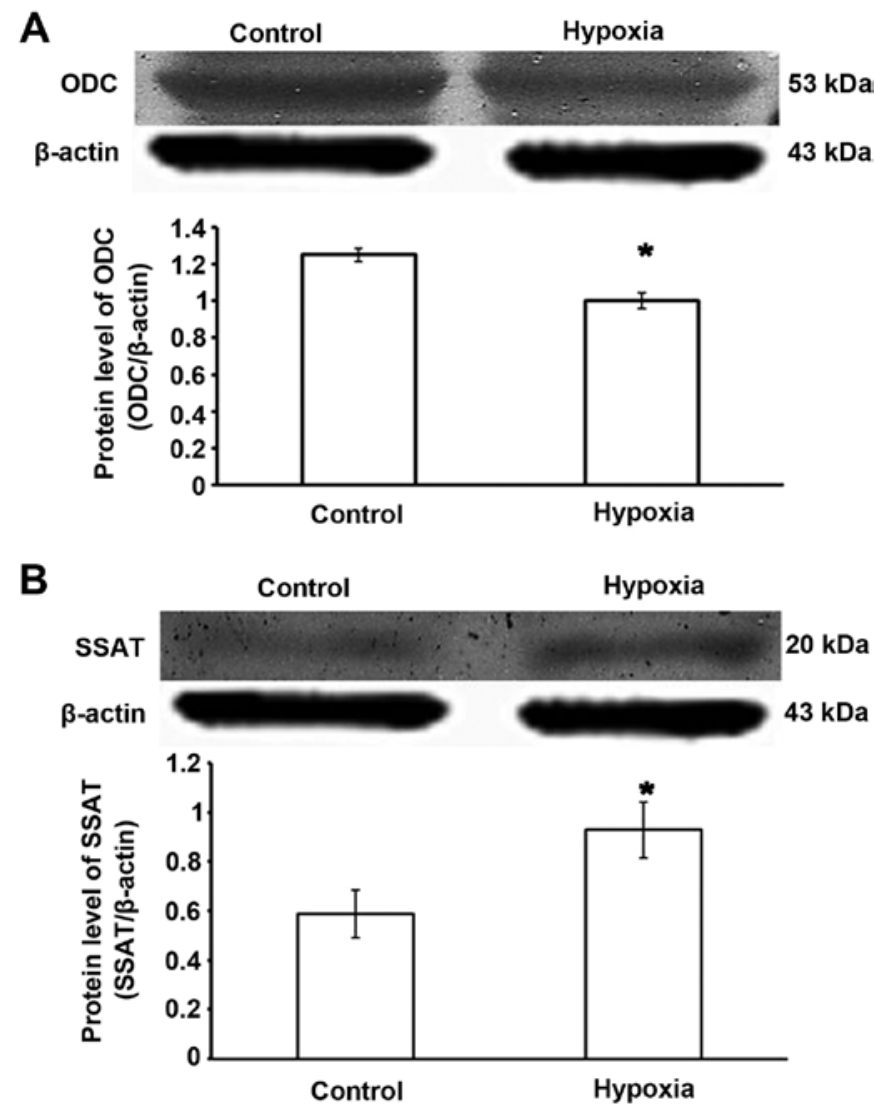

Figure 2. Changes to the key regulatory enzyme for polyamine metabolism under hypoxic conditions. The level of endogenous spermine (Sp) was reflected by the protein expression of (A) ornithine decarboxylase (ODC) and (B) spermidine/spermine N1-acetyltransferase (SSAT). These were examined using western blot analysis. The intensity of each band was quantified by densitometry, and data were normalized to $\beta$-actin. ${ }^{*}$ p $<0.05$ vs. control group. All data are representative of 4 independent experiments.

hypoxia groups $(\mathrm{p}<0.05)$. These results indicated that hypoxia induced a decrease in endogenous Sp (Fig. 2).

Exogenous Sp inhibits the increase in PASMC proliferation caused by chemically-induced hypoxia. To demonstrate the effect of Sp on PASMC proliferation, cell viability was examined by MTT assay (Fig. 3A). We found that exposure to chemically-induced hypoxia for $24 \mathrm{~h}$ significantly promoted PASMC proliferation. At a concentration of 1 and $10 \mu \mathrm{M}, \mathrm{Sp}$ inhibited PASMC proliferation compared with the hypoxia group $(\mathrm{p}<0.05)$; however, $\mathrm{Sp}$ at 0.1 and $100 \mu \mathrm{M}$ had no significant effect on PASMC proliferation under hypoxic conditions $(\mathrm{p}>0.05)$. The CCK-8 assay demonstrated similar results (Fig. 3B). To assess the population of actively synthesizing DNA cells, a BrdU assay was utilized. The fluorescence intensity of DNA reflects the ability of cells to proliferate. Our results revealed that the induction of hypoxia markedly increased cell proliferation compared with the control group $(\mathrm{p}<0.05)$. Sp at 1 and $10 \mu \mathrm{M}$ inhibited PASMC proliferation compared with the hypoxia group $(\mathrm{p}<0.05)$; however, the effect of $\mathrm{Sp}$ at 0.1 and $100 \mu \mathrm{M}$ was not significant ( $>0.05$; Fig. $3 \mathrm{C}$ ).

Exogenous Sp arrests PASMCs at the G1/G0 phase under hypoxic conditions. The cell cycle transition from the G1/ $\mathrm{G} 0$ phase to the $\mathrm{G} 2 / \mathrm{S}$ phase reflects cell proliferation. Therefore, 
A

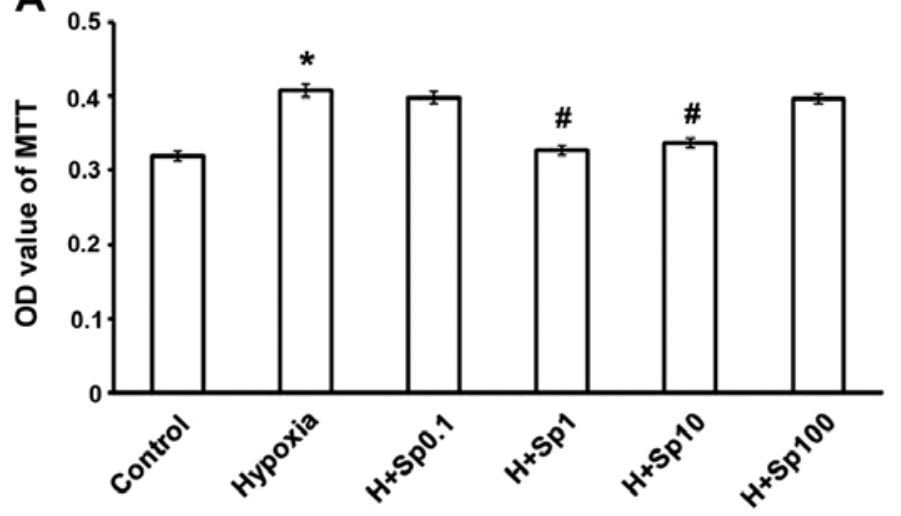

B

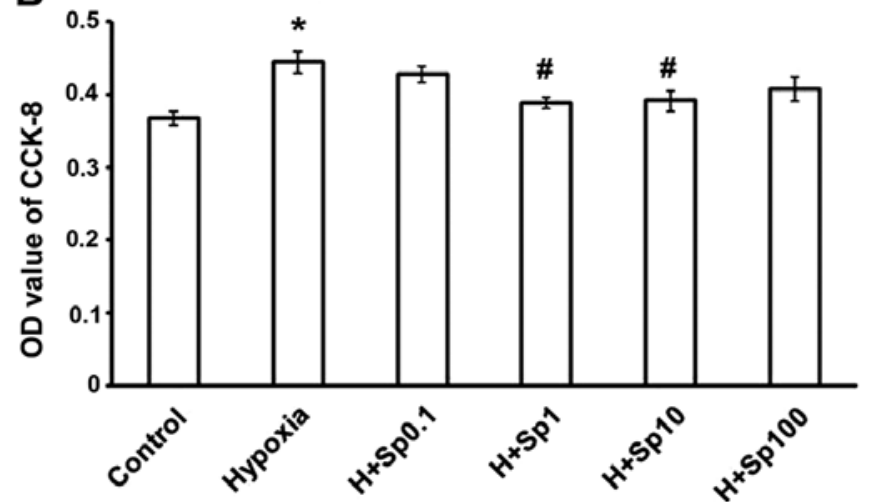

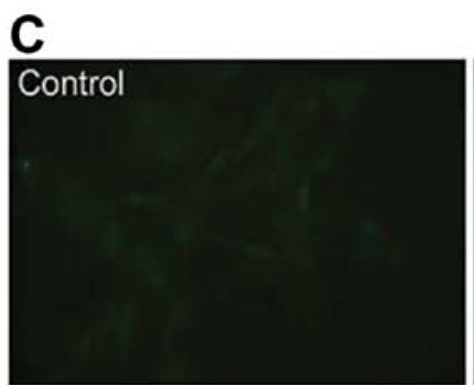
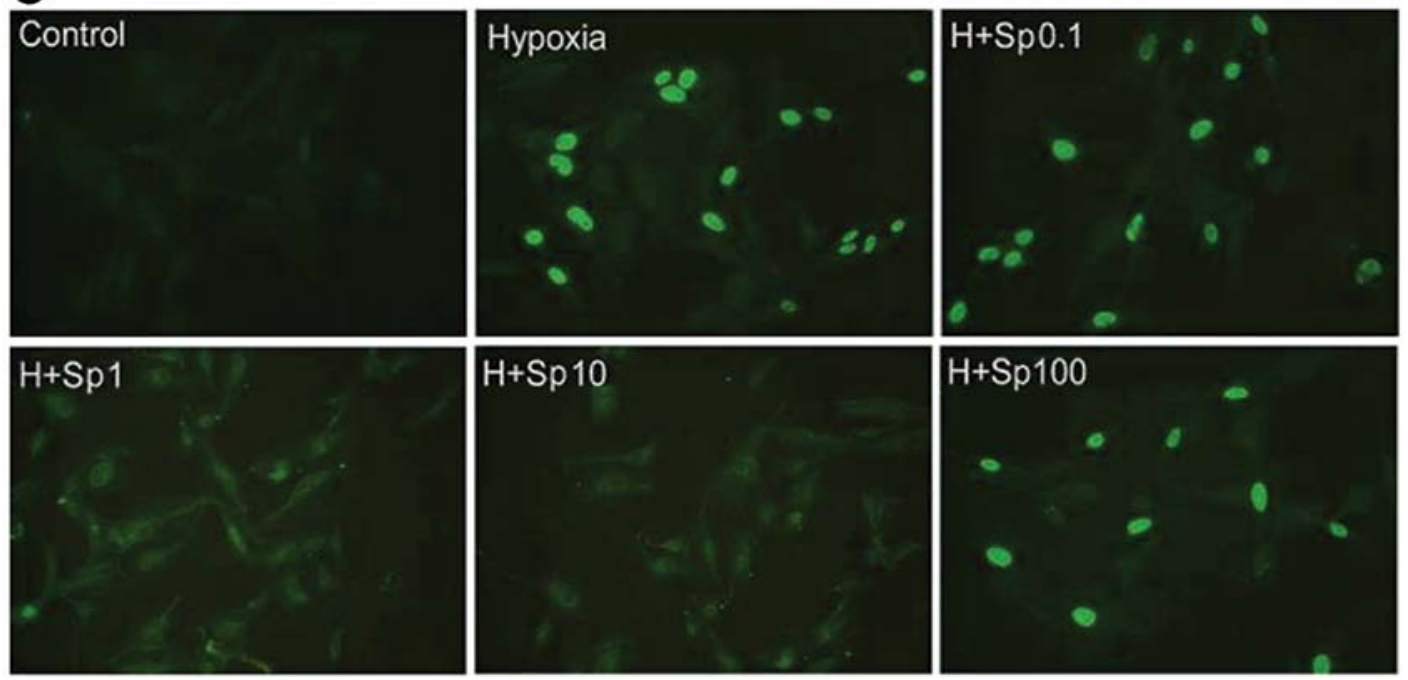

Figure 3. Exogenous spermine (Sp) inhibits chemical hypoxia-induced pulmonary artery smooth muscle cell (PASMC) proliferation. The effects of Sp on PASMC proliferation were analyzed by measuring the optical density (OD) in (A) MTT assay, (B) CCK-8 assay, and (C) the fluorescence intensity of DNA by BrdU incorporation assay. ${ }^{*} \mathrm{p}<0.05$ vs. control group; ${ }^{\#} \mathrm{p}<0.05$ vs. hypoxia group. Data are represented as the means \pm SEM of 8 determinations. H, hypoxia

we wished to determine whether Sp affects the cell cycle of PASMCs under hypoxic conditions. As shown in Fig. 4, the exposure of the PASMCs to hypoxia for $24 \mathrm{~h}$ caused the cells to enter mitosis. Hypoxia also increased the number of PASMCs in the $\mathrm{G} 2 / \mathrm{S}$ phase and decreased the number of PASMCs in the G0/G1 phase $(\mathrm{p}<0.05)$. However, treatment with $\mathrm{Sp}$ at 1 and $10 \mu \mathrm{M}$ weakened the effects of hypoxia on the PASMC cell cycle ( $\mathrm{p}<0.05$ ), although Sp at 0.1 and $100 \mu \mathrm{M}$ did not markedly affect the cycle $(\mathrm{p}>0.05)$.

Exogenous Sp affects the protein expression of cyclin DI and p27 in cultured PASMCs. The expression of cyclin D1 was increased and that of p27 was decreased in the hypoxia group ( $\mathrm{p}<0.05$ vs. control group). Compared with the hypoxia group, treatment with $\mathrm{Sp}$ at 1 and $10 \mu \mathrm{M}$ significantly decreased cyclin D1 expression, and increased p27 expression $(\mathrm{p}<0.05)$; however, Sp at 0.1 and $100 \mu \mathrm{M}$ did not have a significant effect ( $\mathrm{p}>0.05$; Fig. 5).

Protein expression of $p$-ERK, $p$-PI3K and $p$-AKT in cultured PASMCs. Compared with the control group, the induction of hypoxia promoted the phosphorylation of ERK1/2 (Fig. 6A) and increased PI3K and AKT phosphorylation (Fig. 6B and C). Treatment with $\mathrm{Sp}$ at 1 and $10 \mu \mathrm{M}$ reversed the effects of hypoxia on the MAPK and PI3K-AKT pathways $(\mathrm{p}<0.05)$; however, Sp at 0.1 and $100 \mu \mathrm{M}$ was not so effective at reducing the effects of hypoxia ( $>>0.05$ ). The total amount of ERK1/2, $\mathrm{PI} 3 \mathrm{~K}$ and AKT proteins was not significantly altered in the different groups.

\section{Discussion}

HPH, a chronic progressive disease with a poor prognosis, is characterized by pulmonary vascular remodeling and a persistent increase in arterial pressure (15). To explore the mechanisms responsible for the development of HPH and to effectively treat this condition, clinical observations and animal experiments are commonly performed. In previous studies using cell models, injury caused by chemically-induced hypoxia was used to construct $\mathrm{HPH}$ models $(16,17) . \mathrm{CoCl}_{2}$ is a well-known hypoxia mimetic agent that mimics the hypoxic response in many aspects (12). In the present study, we examined the effects of $\mathrm{CoCl}_{2}$ at various concentrations and treatment times on the number of viable PASMCs, and we selected the 

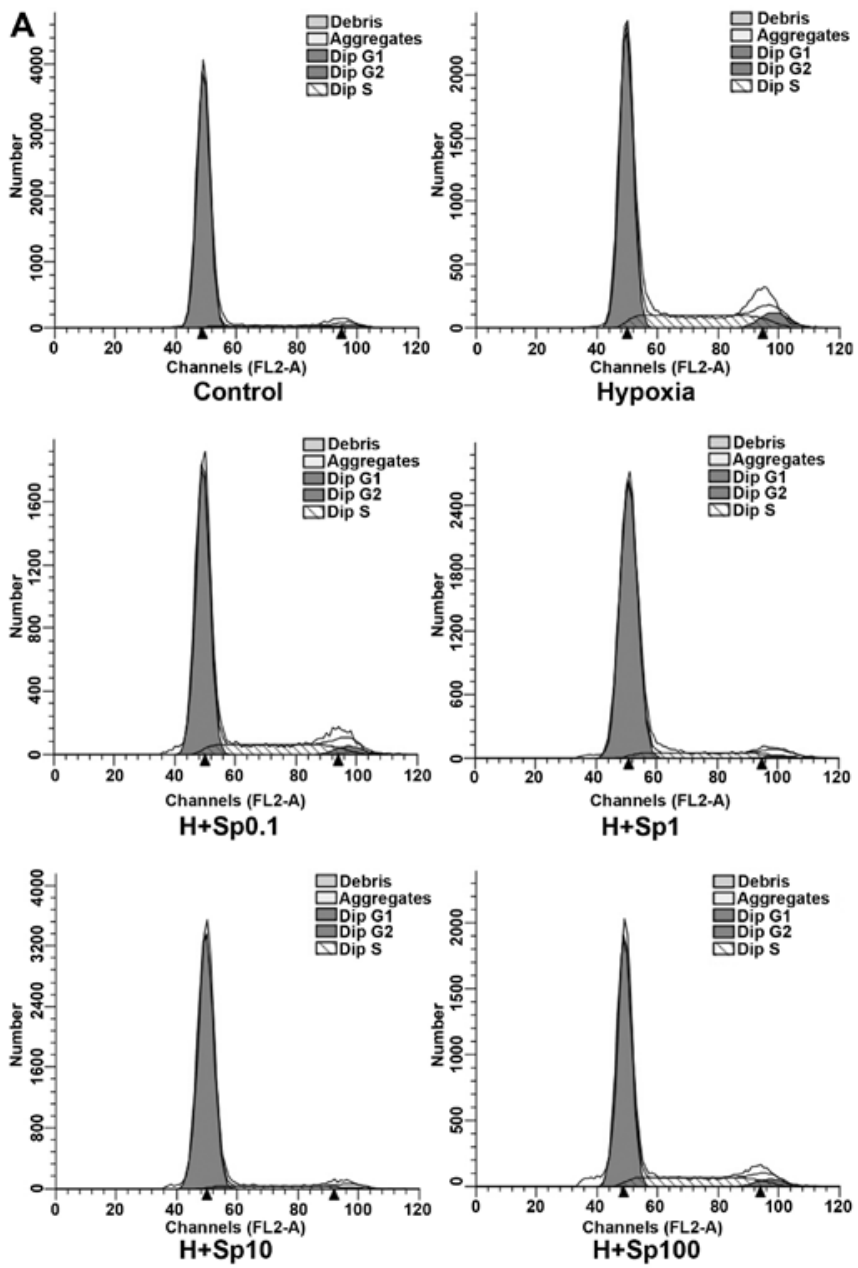

B
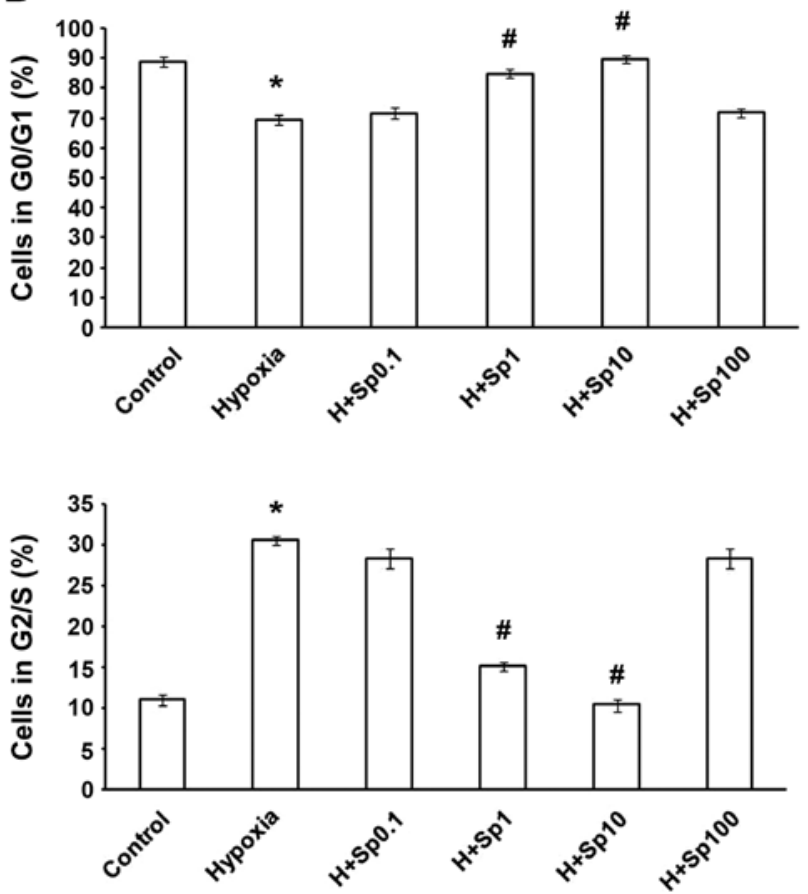

Figure 4. Exogenous spermine (Sp) arrests pulmonary artery smooth muscle cells (PASMCs) in G1/G0 phase under hypoxic conditions. (A) Representative cell cycle histograms measured by flow cytometry. (B) Effects of Sp on the cell cycle of PASMCs. " $\mathrm{p}<0.05$ vs. control group; ${ }^{\#} \mathrm{p}<0.05$ vs. hypoxia group. Data are represented as the means \pm SEM from 3 experiments. $H$, hypoxia.
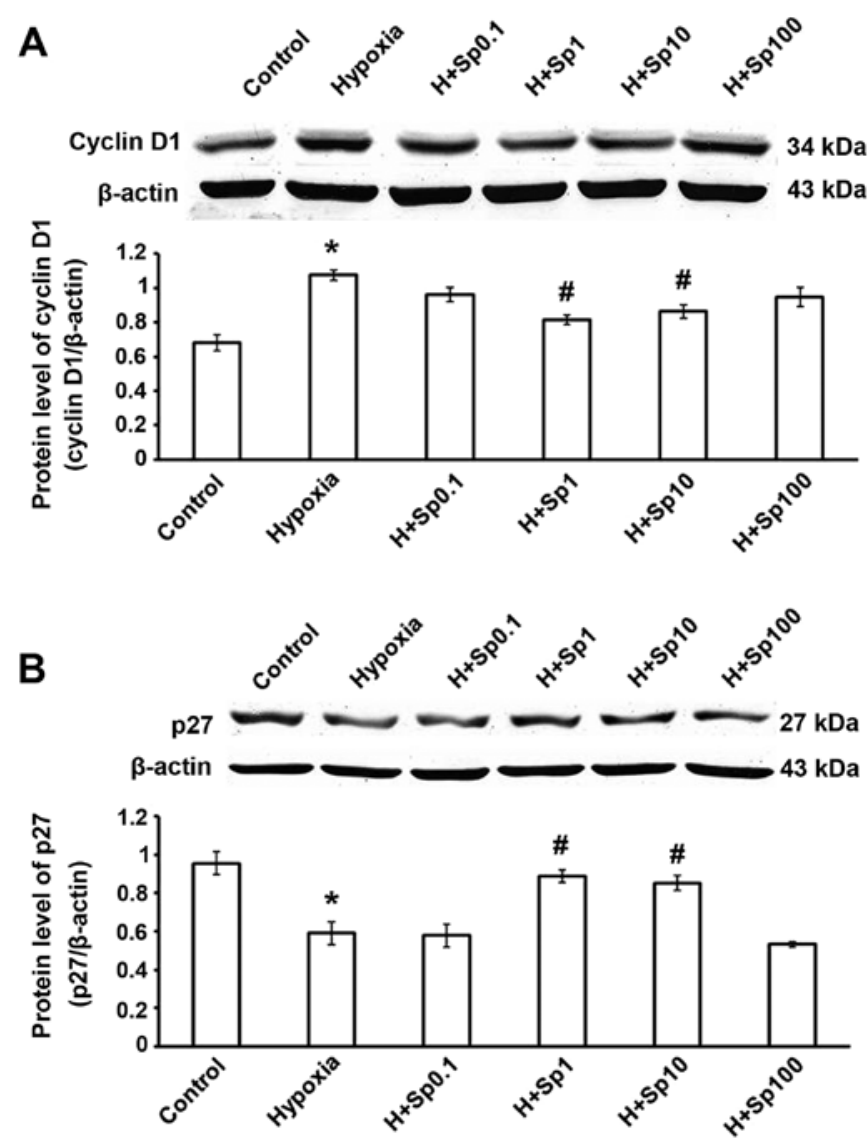

Figure 5. Exogenous spermine affects the protein expression of cyclin D1 and p27 in cultured pulmonary artery smooth muscle cells (PASMCs). The expression of (A) cyclin D1 and (B) p27 was examined by western blot analysis. The intensity of each band was quantified by densitometry, and data were normalized to $\beta$-actin. ${ }^{*} \mathrm{p}<0.05$ vs. control group; ${ }^{\#} \mathrm{p}<0.05$ vs. hypoxia group. All data were from 4 independent experiments. $\mathrm{Sp}$, spermine; $\mathrm{H}$, hypoxia.

concentration of $50 \mu \mathrm{M}$ for $24 \mathrm{~h}$ to establish the cell model of hypoxia, as was done in a previous study (18).

Pulmonary arterial remodeling occurs primarily due to the abnormal proliferation of PASMCs $(2,3)$. Therefore, the inhibition of hypoxia-induced PASMC proliferation exerts anti-remodeling effects. The exact mechanisms responsible for pulmonary arterial remodeling have, however, not been fully elucidated thus far, although certain studies have demonstrated that biologically active media, such as endothelin, vascular endothelial growth factor, nitric oxide, prostacyclin and other factors are involved in this pathological process $(19,20)$. Moreover, the association between pulmonary vascular remodeling and polyamine metabolism has not been investigated to date, to the best of our knowledge.

Polyamines, including Sp, spermidine and putrescine, are non-protein small molecules with polyvalent positive charges and nitrogen. Sp, with four positive charges, has the most prominent biological effect $(10,21)$. Polyamines and their metabolic enzymes play an essential role in a number of normal and pathological processes. ODC and SSAT are involved in the regulation of polyamine metabolism (11). The transcription and translation of ODC promote cell growth and differentiation (13). SSAT is the central molecular regulator of polyamine metabolism $(14,22)$. Polyamine catabolism plays an important 

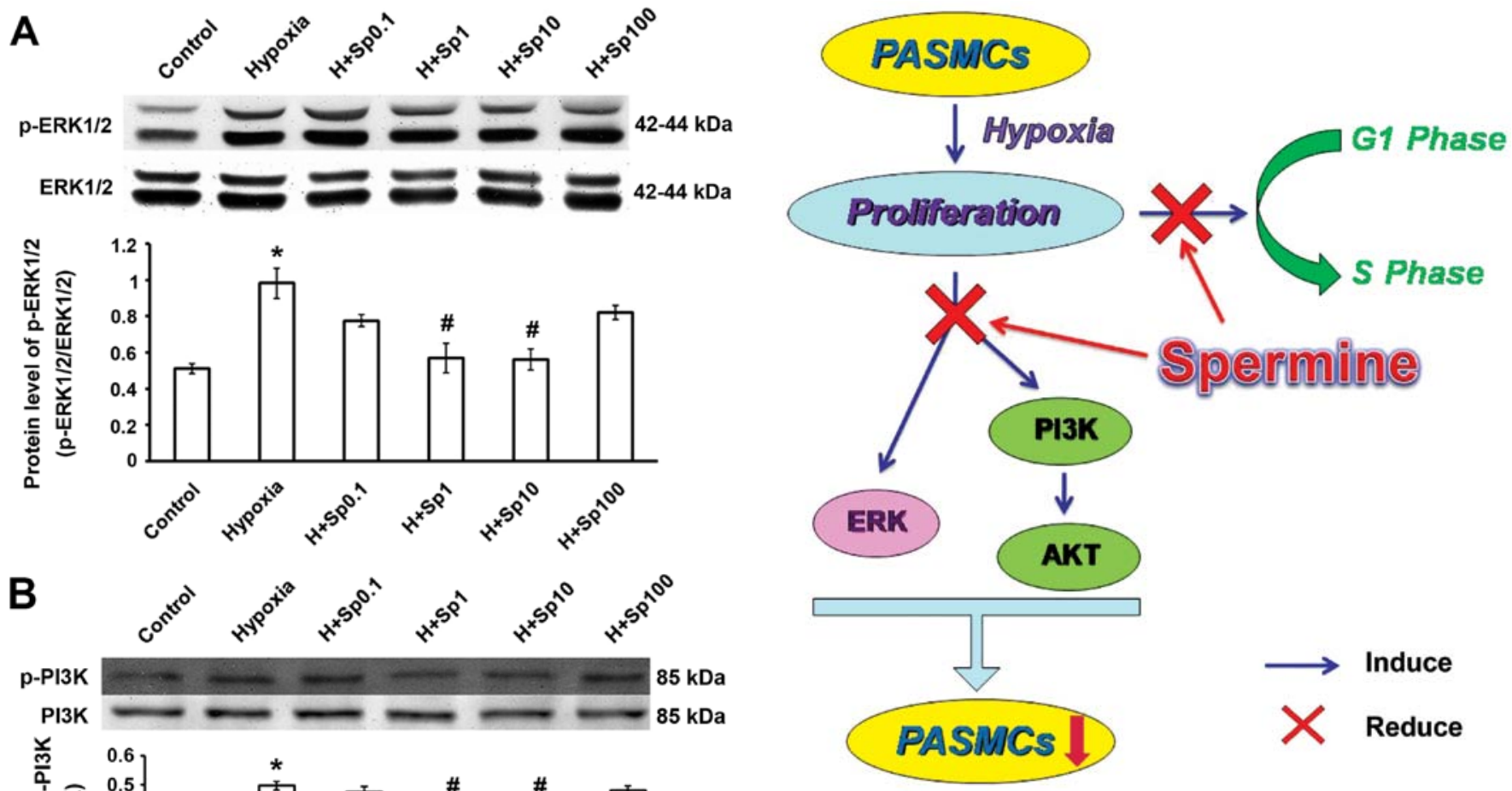

Figure 7. Hypothetical schema outlining the mechanisms through which exogenous spermine inhibites the proliferation of pulmonary artery smooth muscle cells (PASMCs). Exogenous spermine at concentrations of 1 and $10 \mu \mathrm{M}$ inhibited the of proliferation PASMCs caused by chemically-induced hypoxia via the suppression of extracellular signal-regulated kinase 1/2 (ERK1/2) and phosphatidylinositol 3-kinase (PI3K)/AKT-associated pathways.

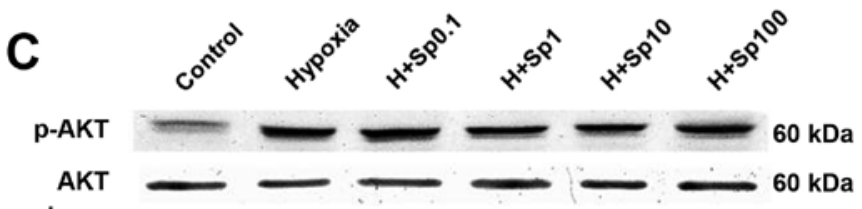

of the main enzymes involved in polyamine biosynthesis, and SSAT is a key enzyme in the terminal degradation of polyamine. Our results suggest that chemically-induced hypoxia causes a decrease in endogenous $\mathrm{Sp}$.

In this study, to examine the effects of Sp on PASMC proliferation, cell viability was measured by MTT assay, CCK- 8 assay and BrdU incorporation assay. Our results demonstrated that chemically-induced hypoxia significantly promoted PASMC proliferation and affected the key enzymes involved in polyamine metabolism, ODC and SSAT. Our data also demonstrated that treatment with exogenous $\mathrm{Sp}(1$ and $10 \mu \mathrm{M})$ inhibited PASMC proliferation.

Cell division consists of two consecutive processes, which are divided into two stages: mitosis (M), the process of nuclear division, and interphase, the interlude between two $M$ phases.

Figure 6. Protein expression of phosphorylated (p-)extracellular signal-regulated kinase 1/2 (ERK1/2), p-PI3K and p-AKT in cultured pulmonary artery smooth muscle cells (PASMCs). The expression of (A) p-ERK1/2, (B) p-PI3K and (C) p-AKT was examined by western blot analysis. The intensity of each band was quantified by densitometry, and data were normalized to total ERK1/2, PI3K and AKT signal. " $\mathrm{p}<0.05$ vs. control group; " $\mathrm{p}<0.05$ vs. hypoxia group. All data are from 4 independent experiments.

role in apoptosis and drug and stress responses, and is involved in the etiology of certain pathological conditions (including cancer) (23). It is not yet clear, however, whether hypoxia, as a type of stress, induces disrupts polyamine metabolism. The results of the present study indicated that chemically-induced hypoxia caused a decrease in ODC expression and an increase in SSAT expression in PASMCs. As is known, ODC is one In addition, the stages of interphase include the G1, S and G2 phases. The G1, S, G2 and M phases are the traditional subdivisions of the standard cell cycle. Cells in the G1 phase, before commitment to DNA replication, enter into a resting state termed G0. Cells in the G0 phase account for the major part of the non-growing, non-proliferating cells in the human body (24). The cell cycle, a key therapeutic target in vascular proliferation-associated diseases, is determined by CDK and CDK inhibitors (CDKIs). Cyclin D1 has previously been recognized as a proto-oncogene, whose main role is to promote cell proliferation (25). Cell growth begins at the G1 phase of the cell cycle, and cyclin D1 is a key protein that regulates the cell cycle in the G1 phase. As one of the main CDK inhibitors, p27 has been previously studied in relation to its modulation of PASMC 
proliferation during mitogenic stimulation, and its overexpression decreases PASMC proliferation (26). Certain studies have suggested that polyamines affect cell cycle progression by regulating proteins, such as cyclins, CDKs and CDKIs $(27,28)$. In the present study, we examined the effects of chemicallyinduced hypoxia and exogenous $\mathrm{Sp}$ on the cell cycle, and on the expression of cyclin D1 and p27. Our results demonstrated that hypoxia promoted the entry of the PASMCs into mitosis by increasing the number of PASMCs in the G2/S phase, decreased the protein expression level of p27 and enhanced the expression of cyclin D1. More importantly, we found that exogenous Sp at 1 and $10 \mu \mathrm{M}$ reversed the effects of hypoxia on the cell cycle and the expression of related proteins. Therefore, the effects of exogenous $\mathrm{Sp}$ are an important mechanism with which to inhibit the proliferation of PASMCs.

ERK1/2 is the most important member of the MAPK family, and can be activated by a variety of extracellular signals, such as ischemia, hypoxia and hormones. ERK1/2 regulates the expression of genes involved in cell growth, proliferation, differentiation and apoptosis (29). Liu et al demonstrated that ERK1/2 induced PASMC proliferation, possibly by increasing cyclin D1 expression and promoting the DNA-binding transcription factor early growth response 1 (Egr-1) and GATA binding protein 4 (GATA-4) (30). Protein kinase B (PKB or AKT) is a major factor of the PI3K signaling pathway. PI3K-AKT signaling pathways regulate cell proliferation, differentiation, survival, migration and other features (31). Previously, it has been reported that PI3K-AKT is associated with PASMC proliferation $(8,9,32)$. In a rat model of pulmonary hypertension, the p-AKT level was shown to be considerably increased, and this was accompanied by the downregulation of p53 and p27 and the upregulation of cyclin D1 expression (33). In the present study, we found that hypoxia promoted the expression of p-ERK1/2, p-PI3K and p-AKT, and that Sp at 1 and $10 \mu \mathrm{M}$ prevented the effects of hypoxia on the MAPK and PI3K-AKT pathways.

In conclusion, in the present study, we firstly found that hypoxia caused polyamine metabolic disorder and human PASMC proliferation, and exogenous Sp at 1 and $10 \mu \mathrm{M}$ inhibited the increase in PASMC proliferation caused by chemically-induced hypoxia via the suppression of the ERK1/2- and PI3K/AKT-associated pathways. As lower $(0.1 \mu \mathrm{M})$ or higher $(100 \mu \mathrm{M})$ concentrations of Sp did not have a significant effect, which may be related to the inbalance of polyamine metabolism, further studies are warranted to investigate this matter. It is thus suggested that Sp may serve as a novel, specific and attractive therapeutic agent for the treatment of HPH (Fig. 7).

\section{Acknowledgements}

The present study was supported by grants from the National Natural Science Foundation of China (nos. 81070123, 81270311, 81270273 and 81200160), and the Natural Science Foundation of Heilongjiang (no. LC201430).

\section{References}

1. Raguso CA, Guinot SL, Janssens JP, Kayser B and Pichard C: Chronic hypoxia: common traits between chronic obstructive pulmonary disease and altitude. Curr Opin Clin Nutr Metab Care 7: 411-417, 2004
2. Stenmark KR, Fagan KA and Frid MG: Hypoxia-induced pulmonary vascular remodeling: cellular and molecular mechanisms. Circ Res 99: 675-691, 2006.

3. Pak O, Aldashev A, Welsh D and Peacock A: The effects of hypoxia on the cells of the pulmonary vasculature. Eur Respir J 30: 364-372, 2007.

4. Yang G, Wu L, Bryan S, Khaper N, Mani S and Wang R: Cystathionine gamma-lyase deficiency and overproliferation of smooth muscle cells. Cardiovasc Res 86: 487-495, 2010.

5. Sherr CJ and Roberts JM: Inhibitors of mammalian G1 cyclin-dependent kinases. Genes Dev 9: 1149-1163, 1995.

6. Tsai YC, Lee YM, Hsu CH, Leu SY, Chiang HY, Yen MH and Cheng PY: The effect of ferulic acid ethyl ester on leptin-induced proliferation and migration of aortic smooth muscle cells. Exp Mol Med 47: e180, 2015.

7. Rabinovitch M: Molecular pathogenesis of pulmonary arterial hypertension. J Clin Invest 118: 2372-2379, 2008.

8. Liu Y and Fanburg BL: Serotonin-induced growth of pulmonary artery smooth muscle requires activation of phosphatidylinositol 3-kinase/serine-threonine protein kinase B/ mammalian target of rapamycin/p70 ribosomal S6 kinase 1. Am J Respir Cell Mol Biol 34: 182-191, 2006.

9. Goncharova EA: PI3K is required for proliferation and migration of human pulmonary artery smooth muscle cells. Am J Respir Cell Mol Biol 283: 354-363, 2002.

10. Heby O, Sarna GP, Marton LJ, Omine M, Perry S and Russell DH: Polyamine content of AKR leukemic cells in relation to the cell cycle. Cancer Res 33: 2959-2964, 1973.

11. Hasegawa S, Nakano M, Hamana K, Taniguchi Y, Iwasaki T, Kanda T, Suzuki T and Nagai R: Decrease in myocardial polyamine concentration in rats with myocardial infarction. Life Sci 60: 1643-1650, 1997.

12. Goldberg MA, Dunning SP and Bunn HF: Regulation of the erythropoietin gene: evidence that the oxygen sensor is a heme protein. Science 242: 1412-1415, 1988.

13. Shantz LM and Pegg AE: Translational regulation of ornithine decarboxylase and other enzymes of the polyamine pathway. Int J Biochem Cell Biol 31: 107-122, 1999.

14. Wang Y, Devereux W, Stewart TM and Casero RA Jr: Characterizatin of the interaction between the transcription factors human polyamine modulated factor (PMF-1) and NF-E2-related actor(Nrf-2) in the transcriptional regulation of the spermidine/spermine N1-acetyltransferase (SSAT) gene. Biochem J 355: 45-49, 2001.

15. Cogolludo A, Moreno L and Villamor E: Mechanisms controlling vascular tone in pulmonary arterial hypertension: implications for vasodilator therapy. Pharmacology 79: 65-75, 2007.

16. Hartwig K, Fackler V, Jaksch-Bogensperger H, Winter S, Furtner T, Couillard-Despres S, Meier D, Moessler H and Aigner L: Cerebrolysin protects PC12 cells from $\mathrm{CoCl}_{2}$-induced hypoxia employing GSK3 $\beta$ signaling. Int J Dev Neurosci 38: 52-58, 2014.

17. Zhong X, Lin R, Li Z, Mao J and Chen L: Effects of Salidroside on cobalt chloride-induced hypoxia damage and mTOR signaling repression in PC12 cells. Biol Pharm Bull 37: $1199-1206,2014$.

18. Li Y, Liu G, Cai D, Pan B, Lin Y, Li X, Li S, Zhu L, Liao X and Wang $\mathrm{H}: \mathrm{H}_{2} \mathrm{~S}$ inhibition of chemical hypoxia-induced proliferation of HPASMCs is mediated by the upregulation of COX-2/PGI2. Int J Mol Med 33: 359-366, 2014.

19. Humbert M, Morrell NW, Archer SL, Stenmark KR, MacLean MR, Lang IM, Christman BW, Weir EK, Eickelberg O, Voelkel NF and Rabinovitch M: Cellular and molecular pathobiology of pulmonary arterial hypertension. J Am Coll Cardiol 43 (Suppl S): 13S-24S, 2004.

20. Jeffery TK and Morrell NW: Molecular and cellular basis of pulmonary vascular remodeling in pulmonary hypertension. Prog Cardiovasc Dis 45: 173-202, 2002.

21. Shah N, Thomas T, Shirahata A, Sigal LH and Thomas TJ: Activation of nuclear factor kappaB by polyamines in breast cancer cells. Biochemistry 38: 14763-14774, 1999.

22. Matsui-Yuasa I, Otani S, Yukioka K, Goto H and Morisawa S: Two mechanisms of spermidine/spermine N1-acetyltransferase-induction. Arch Biochem Biophys 268: 209-214, 1989.

23. Casero RA and Pegg AE: Polyamine catabolism and disease. Biochem J 421: 323-338, 2009.

24. Vermeulen K, Van Bockstaele DR and Berneman ZN: The cell cycle: a review of regulation, deregulation and therapeutic targets in cancer. Cell Prolif 36: 131-149, 2003. 
25. Inaba T, Matsushime $H$, Valentine M, Roussel MF, Sherr CJ and Look AT: Genomic organization, chromosomal localization, and independent expression of human cyclin D genes. Genomics 13: 565-574, 1992

26. Fouty BW, Grimison B, Fagan KA, Le Cras TD, Harral JW, Hoedt-Miller M, Sclafani RA and Rodman DM: p27(Kip1) is important in modulating pulmonary artery smooth muscle cell proliferation. Am J Respir Cell Mol Biol 25: 652-658, 2001.

27. Wilcken NR, Prall OW, Musgrove EA and Sutherland RL: Inducible overexpression of cyclin D1 in breast cancer cells reverses the growth-inhibitory effects of antiestrogens. Clin Cancer Res 3: 849-854, 1997.

28. Hong J, Shah NN, Thomas TJ, Gallo MA, Yurkow EJ and Thomas T: Differential effects of estradiol and its analogs on cyclin D1 and CDK4 expression in estrogen receptor positive MCF-7 and estrogen receptor-transfected MCF-10AEwt5 cells. Oncol Rep 5: 1025-1033, 1998.

29. Roskoski R Jr: ERK1/2 MAP kinases: structure, function, and regulation. Pharmacol Res 66: 105-143, 2012.
30. Liu Y, Suzuki YJ, Day RM and Fanburg BL: Rho kinase-induced nuclear translocation of ERK1/ERK2 in smooth muscle cell mitogenesis caused by serotonin. Circ Res 95: 579-586, 2004.

31. Faes S and Dormond O: PI3K and AKT: Unfaithful partners in cancer. Int J Mol Sci 16: 21138-21152, 2015.

32. Ogawa A, Firth AL, Smith KA, Maliakal MV and Yuan JX PDGF enhances store-operated $\mathrm{Ca}^{2+}$ entry by upregulating STIM1/Orail via activation of Akt/mTOR in human pulmonary arterial smooth muscle cells. Am J Physiol Cell Physiol 302: C405-C411, 2012.

33. Ravi Y, Selvendiran K, Meduru S, Citro L, Naidu S, Khan M, Rivera BK, Sai-Sudhakar CB and Kuppusamy P: Dysregulation of PTEN in cardiopulmonary vascular remodeling induced by pulmonary hypertension. Cell Biochem Biophys 67: 363-372, 2013. 